\title{
CORRECTION
}

\section{Correction: Interbacterial mechanisms of colonization resistance and the strategies pathogens use to overcome them}

Matthew T. Sorbara ${ }^{1}$ and Eric G. Pamer ${ }^{1,2}$

Mucosal Immunology (2019) 12:840; https://doi.org/10.1038/s41385-019-0151-7

Correction to: Mucosal Immunology (2019) 12: 1-19. https://doi. org/10.1038/s41385-018-0053-0; published online 9 July 2018.
The original version of this article contained an error in the published figures, where they appeared in black and white. These have now been corrected to display in colour.

${ }^{1}$ Immunology Program, Sloan Kettering Institute, Memorial Sloan-Kettering Cancer Center, New York, NY 10065, USA and ${ }^{2}$ Center for Microbes, Inflammation and Cancer, Memorial Sloan-Kettering Cancer Center, New York, NY 10065, USA

Correspondence: Matthew T. Sorbara (sorbaram@mskcc.org) or Eric G. Pamer (pamere@mskcc.org)

Published online: 22 February 2019 